\title{
Specific role of combination aclidinium: formoterol in the treatment of chronic obstructive pulmonary disease
}

Maria Gabriella Matera'

Alessandro Sanduzzi ${ }^{2}$

Mario Cazzola ${ }^{3}$

'Department of Experimental Medicine, Second University of Naples, ${ }^{2}$ Department of Respiratory Diseases, Monaldi Hospital, University Federico II, Naples, ${ }^{3}$ Department of Systems Medicine, University of Rome Tor Vergata, Rome, Italy
Correspondence: Maria Gabriella Matera Department of Experimental Medicine, Second University of Naples, via Santa Maria di Costantinopoli, I6, 80I38 Naples, Italy

Email mariagabriella.matera@unina2.it
This article was published in the following Dove Press journal:

International Journal of COPD

5 January 2016

Number of times this article has been viewed
Abstract: Co-administration of a long-acting $\beta_{2}$-agonist and a long acting muscarinic antagonist produces superior bronchodilation compared with their individual effects. Our preclinical data indicated that combining aclidinium bromide (ACLI) and formoterol fumarate (FORM) provides synergistic benefit on smooth muscle relaxation of both large and small human airways. Data from more than 2,000 patients in eleven clinical trials documented that ACLI/FORM, a twicedaily fixed-dose combination, produces a greater degree of bronchodilation than ACLI or FORM monotherapy alone and is safe and well tolerated. Two large key trials have shown that there is a benefit in using ACLI/FORM when the clinical target is the variability of symptoms and mainly nighttime and/or early morning symptoms. ACLI/FORM is the only long acting muscarinic antagonist/long acting $\beta_{2}$-agonist fixed-dose combination that has been studied for this therapeutic indication.

Keywords: aclidinium, formoterol, fixed-dose combination, COPD, symptoms

\section{Background}

A solid body of evidence indicates that simultaneous administration of a long-acting $\beta_{2}$-agonist (LABA) and a long-acting muscarinic antagonist (LAMA) produces superior bronchodilation compared with their individual effects. ${ }^{1-7}$ In addition, the examination of the literature reveals that the majority of the patients reported outcomes such as dyspnea, other symptoms, rescue medication use, and quality of life, improve more with free LABA/ LAMA combinations than with the individual components administered alone. ${ }^{8}$

Simultaneous stimulation of $\beta_{2}$-adrenoceptors and inhibition of the action of acetylcholine at muscarinic receptors with antimuscarinic agent may elicit a larger bronchodilation by relaxing the airway smooth muscle (ASM) in a more complete manner. ${ }^{9}$ Furthermore, the intracellular crosstalk makes the $\beta_{2}$-adrenoceptors and the muscarinic pathways so linked to explain the favorable ASM relaxation induced by LABA/LAMA combinations. ${ }^{10,11}$

The disparity in the duration of action of the twice-daily LABAs and a once-daily LAMA, and the differences in the devices used to deliver the single medications, render these free combinations inconvenient and unpredictable, especially if focused on the adherence to prescribed treatment. ${ }^{12,13}$ Therefore, several fixed-dose combinations (FDCs) of once- or twice-daily LABAs and LAMAs in a single delivery device have been developed. ${ }^{14}$

In this review, we will focus on the clinical and functional benefits that can be achieved in many COPD patients through the use of the twice-daily aclidinium bromide/ formoterol fumarate (ACLI/FORM) FDC. 


\section{Characteristics of monocomponents}

ACLI is a twice-daily LAMA developed for maintenance treatment of COPD. ${ }^{15}$ Preclinical data showed that it has an intriguing pharmacodynamic and pharmacokinetic profile. ${ }^{15}$ A recent translation study has compared, in the same patients and human tissues, the onset of action of ACLI, glycopyrronium, and tiotropium, the three LAMAs currently approved for the treatment of COPD. ${ }^{16}$ Experiments carried out in human-isolated bronchi documented a very fast and concentration-dependent onset of action for glycopyrronium, whereas both ACLI and tiotropium were able to induce 50\% relaxation of ASM only at the highest concentration administered in the baths, but ACLI was faster than tiotropium in relaxing human-isolated bronchi. In COPD patients, ACLI and glycopyrronium elicited a faster onset of action and induced a larger bronchodilation in the first 90 minutes of inhalation when compared with tiotropium. Key Phase III trials documented that ACLI $400 \mu \mathrm{g}$ twice-daily shows significant improvements in lung function and other important patient reported outcomes, such as health-related quality of life, dyspnea, and nighttime/early morning symptoms, and is safe. ${ }^{15}$ A recent Cochrane systematic review has shown that, in comparison with placebo, ACLI led to an improvement in quality of life and a reduction in hospitalizations due to severe exacerbations in patients with moderate-to-severe stable COPD. ${ }^{17}$

The well-known pharmacodynamic characteristics of FORM make judging this agent as the most suitable LABA in a FDC with a twice-daily LAMA. FORM causes a fast bronchodilation that arises within a few minutes after inhalation, is dose-dependent and not significantly different from that caused by salbutamol. ${ }^{18,19}$ In patients with COPD, FORM $(12-36 \mu \mathrm{g})$ significantly improves lung function over 12 hours. ${ }^{20}$ Moreover, FORM is effective, safe, and well tolerated. ${ }^{21}$ The results of many multicenter clinical trials indicate that FORM is an efficacious therapeutic option in the treatment of COPD. ${ }^{21}$

\section{Preclinical development of ACLI/ FORM combination}

A preclinical study explored the potential for a pharmacological interaction between ACLI and FORM on the relaxation of human large and small airways. ${ }^{22}$

Both ACLI and FORM were able to induce potent, significant, and long-lasting relaxation of large airways. Interestingly, the coadministration of low concentrations of these drugs caused a reduction in electrical field stimulation- or acetylcholine-induced ASM tone by acting in a synergistic way.
The electrical field stimulation-induced contractile response was inhibited by both ACLI and FORM in a time-dependent manner, a confirmation of the long duration of action of these compounds. Intriguingly, the synergistic interaction elicited by the coadministration of ACLI and FORM allowed a noticeably more rapid reduction of the electrical field stimulation-induced contraction of ASM, and this relaxant effect was sustained for up to 6 hours after administration of the drugs. ACLI and FORM were also able to potently relax small airways, although FORM, but not ACLI, completely relaxed them. Furthermore, the combination was particularly effective at inhibiting the contractile response of small airways, with a wider extent of synergistic interaction from low-to-high concentrations than in larger airways.

These results suggested that combining ACLI and FORM provides synergistic benefit on ASM relaxation of both large and small airways and fully supported the clinical development of ACLI/FORM FDC.

\section{Clinical development of ACLI/ FORM FDC}

Several reviews have already described the clinical development of ACLI/FORM FDC. ${ }^{23-27}$ The common conclusion of these reviews, based on efficacy and safety data from more than 2,000 patients in eleven clinical trials is that ACLI/ FORM FDC produces a greater degree of bronchodilation than ACLI or FORM monotherapy alone. However, the pivotal trials do not allow to establish yet whether this benefit translates into improved long-term outcomes of decreased exacerbation frequency, improved quality of life, and decreased disease-specific mortality, although ACLI/ FORM FDC increases the percentage of patients with an improvement in symptoms and health-related quality of life compared with monotherapies. The combination appears to be safe and well tolerated in clinical trials.

Even with these highlighted shortcomings, Astra Zeneca announced on 24 November 2014 that Duaklir ${ }^{\circledR}$ Genuair $^{\circledR}$ (ACLI/FORM FDC, 340/12 $\mu \mathrm{g}$ ) was granted Marketing Authorization by the European Commission to be used as a maintenance bronchodilator treatment for airflow obstruction and relief of symptoms in adult patients with COPD ${ }^{28}$ In fact, the Committee for Medicinal Products for Human Use concluded that benefits of ACLI/FORM FDC are greater than its risks and recommended its approval for use in the European Union. ${ }^{29}$ However, the Committee for Medicinal Products for Human Use remarked that the results of clinical trial showed that ACLI/FORM FDC significantly improved lung function in patients with COPD compared 
with placebo, but the improvement was small when ACLI/ FORM FDC was compared with FORM.

\section{Role of ACLI/FORM FDC in COPD treatment}

The first major difference between ACLI/FORM FDC and other FDCs that are already granted Marketing Authorisation by the European Commission is that ACLI/FORM FDC is the only twice-daily FDC.

It must still be determined whether it is preferable to administer a bronchodilator on a once- or twice-daily basis. The simplification of the dosing schedule with once-daily dosing might increase treatment adherence, ${ }^{30}$ but we must highlight that there are no published data yet to support improved adherence or effectiveness with ACLI/FORM FDC compared to other LABA/LAMA FDCs. Moreover, dosing frequency seems to be of greater importance to pulmonologists than primary care physicians. ${ }^{31}$

Beeh and Beier suggested that the longer duration of action of once-daily bronchodilators causes not only an increase in the net area under the curve time/air flow improvement ratios increases and in morning $\mathrm{FEV}_{1}$ after the last inhalation ("through" $\mathrm{FEV}_{1}$ ) but also on average, less dyspnea, and facilitated lung emptying during tidal breathing at rest throughout the whole day. ${ }^{32}$ Duration of effect and dosing interval or frequency (eg, once or twice daily) are not necessarily the same, although they are closely interrelated and are a function of maintenance dose and pharmacokinetics. ${ }^{33}$ Intriguingly, at least in theory, with the same total daily dose, a twice-daily regimen provides higher bronchodilation at trough than a once-daily regimen according to data from a population pharmacodynamic model of the longitudinal $\mathrm{FEV}_{1}$ response to ACLI in COPD patients. ${ }^{34}$

In any case, the mean changes from baseline in trough $\mathrm{FEV}_{1}$ after 6-month treatment were with ACLI/FORM 400/12 $\mu \mathrm{g}$ delivered dose $143 \mathrm{~mL}$ vs placebo (treatment differences: $85 \mathrm{~mL}$ vs formoterol $12 \mu \mathrm{g}$, and $26 \mathrm{~mL}$ vs ACLI $400 \mu \mathrm{g}),{ }^{35}$ with glycopyrronium/indacaterol 50/110 $\mu \mathrm{g}$ $160 \mathrm{~mL}$ (treatment differences: $70 \mathrm{~mL}$ vs indacaterol $150 \mu \mathrm{g}$, and $90 \mathrm{~mL}$ vs glycopyrronium $50 \mu \mathrm{g}),{ }^{36}$ with umeclidinium/ vilanterol 62.5/25 $\mu \mathrm{g}$ 208-211 mL (treatment differences: $90 \mathrm{~mL}$ vs vilanterol $25 \mu \mathrm{g}$, and $22 \mathrm{~mL}$ vs umeclidinium $125 \mu \mathrm{g}$ ), ${ }^{37}$ with tiotropium/olodaterol $5 / 5 \mu \mathrm{g} 136 \mathrm{~mL}$ (treatment differences: $85 \mathrm{~mL}$ vs olodaterol $5 \mu \mathrm{g}$, and $60 \mathrm{~mL}$ vs tiotropium $5 \mu \mathrm{g}) .^{38}$ In the absence of head-to-head comparison it is difficult to determine whether the modest differences between the different FDCs have a real clinical value. Rather, observing the values of trough $\mathrm{FEV}_{1}$ generated by the different FDCs, it becomes obvious that the question is whether the doses of the bronchodilators approved for the treatment of COPD are delivered into the lung at isoeffective concentrations. We believe that the lack of isoeffectiveness explains the differences in bronchorelaxation that have been found for different medications belonging to the same class of drugs. ${ }^{11}$

Another important feature of ACLI/FORM FDC is that it induces a rapid bronchodilation, within 5 minutes, ${ }^{35}$ and is probably the FDC with the fastest onset of action, considering the characteristics of the individual components. A recent study has shown that ACLI plus FORM not only induced a faster onset of action compared with that produced by monocomponents but also showed a synergistic interaction that at 5 minutes postadministration was higher than $50 \%$ when compared with the expected additive effect and remained constant after 2 hours postdose. ${ }^{39}$

Since it is not yet clear what is the importance of the rapidity of bronchodilator onset of action in COPD, no study has compared yet the onset of action of different FDCs. On repeated dosing, fast onset may not be particularly useful in patients who take their treatment regularly and have relatively stable symptoms. ${ }^{33}$ Conversely, it might be useful in patients with suboptimal adherence to treatment, in view of the fact that fast-onset bronchodilation would translate into fast relief of dyspnea (as in the case of salbutamol used as rescue medication) and perceived rapid efficacy could reinforce compliance. ${ }^{33}$ Since there is a significant correlation between acute bronchodilator effect and symptom improvement, which is strongest in patients with baseline hyperinflation, ${ }^{40}$ it has been hypothesized that fast onset of action could also be useful in patients with more variable symptoms. ${ }^{33}$

There is solid evidence now that patients with COPD experience symptoms all throughout the day. ${ }^{40}$ However, the perception of the magnitude of symptoms by patients varies over the course of the day and even over the course of the week. ${ }^{41}$ The majority of patients with COPD suffer from symptoms at night. ${ }^{42,43}$ Many patients also suffer from bothersome symptoms early in the morning. . $^{41,44,45}$ Those with either or both of the symptoms at night or symptoms in early morning are associated with poorer health status compared to those without. ${ }^{46}$ Patients with COPD expect their treatment to provide fast symptom relief, greater mobility, and improvement in morning activities. ${ }^{47}$ Improved disease management may reduce nighttime/early morning symptoms and improve health status in patients with COPD. ${ }^{46}$

Despite the described evidence of variation in perceived symptoms during the day and the documentation that diurnal 
dyspnea is a good predictor of mortality in stable COPD patients ${ }^{48}$ this appears to be hardly considered in actual treatment plans. Apparently, patients with more variable symptoms tend to be more likely to adapt their treatment in response to worsening symptoms. ${ }^{41}$ This is definitely not the best approach to possibly reduce the variability of symptoms. Consequently, there is a need to provide health care professionals with treatment strategies able to lessen the impact of this variation. ${ }^{48}$

The ACLI formoterol-COPD (ACLI FORM-COPD) key study, a 24-week double-blind, parallel-group, active- and placebo-controlled, multicenter Phase III study, conducted at 193 centers in Europe and South Africa, also explored the effects on symptoms of two doses of ACLI/FORM FDC (400/12 and $400 / 6 \mu \mathrm{g}$ ) vs the monotherapy components (ACLI $400 \mu \mathrm{g}$ and FORM $12 \mu \mathrm{g}$ ) and placebo (Table 1). ${ }^{35}$ The total Exacerbations of COPD Tool-Respiratory Symptoms (EXACT-RS) scale, a patient-reported outcome measure designed to evaluate respiratory symptoms in clinical trials, and the nighttime and early morning symptoms scores, were used to explore changes from baseline in COPD symptoms. The EXACT-RS utilizes eleven respiratory symptom items from the existing and validated 14-item EXACT, which measures symptoms of exacerbation, and is a reliable, valid, and responsive measure of respiratory symptoms of COPD suitable for use in natural history studies and clinical trials. ${ }^{49}$ Nighttime/early morning symptoms were assessed using a 14-item Nighttime and Early Morning Symptoms questionnaire completed every morning. The psychometric qualities of the Nighttime and Early Morning Symptoms questionnaires have been evaluated and final instruments developed. ${ }^{50,51}$ Higher EXACT-RS, nighttime and early morning symptoms scores indicated more severe symptoms. The improvements in EXACT-RS with both ACLI/FORM FDC doses were significantly larger compared with the single agents. Both doses of ACLI/FORM FDC significantly improved overall nighttime symptom severity score vs placebo and monotherapies, with the exception of the FDC 400/12 $\mu \mathrm{g}$ dose vs FORM $12 \mu \mathrm{g}$. Changes from baseline in early morning symptoms scores with both ACLI/FORM FDC doses achieved statistical significance compared with placebo and ACLI monotherapy, whereas only FDC 400/6 $\mu \mathrm{g}$ significantly improved early morning symptoms scores vs FORM. Compared with placebo, both ACLI/FORM FDCs significantly improved Transition Dyspnea Index focal score above the minimum clinically important difference of 1 unit at week 24 and at all other time points. Both ACLI/FORM FDCs also showed numerically greater improvements vs

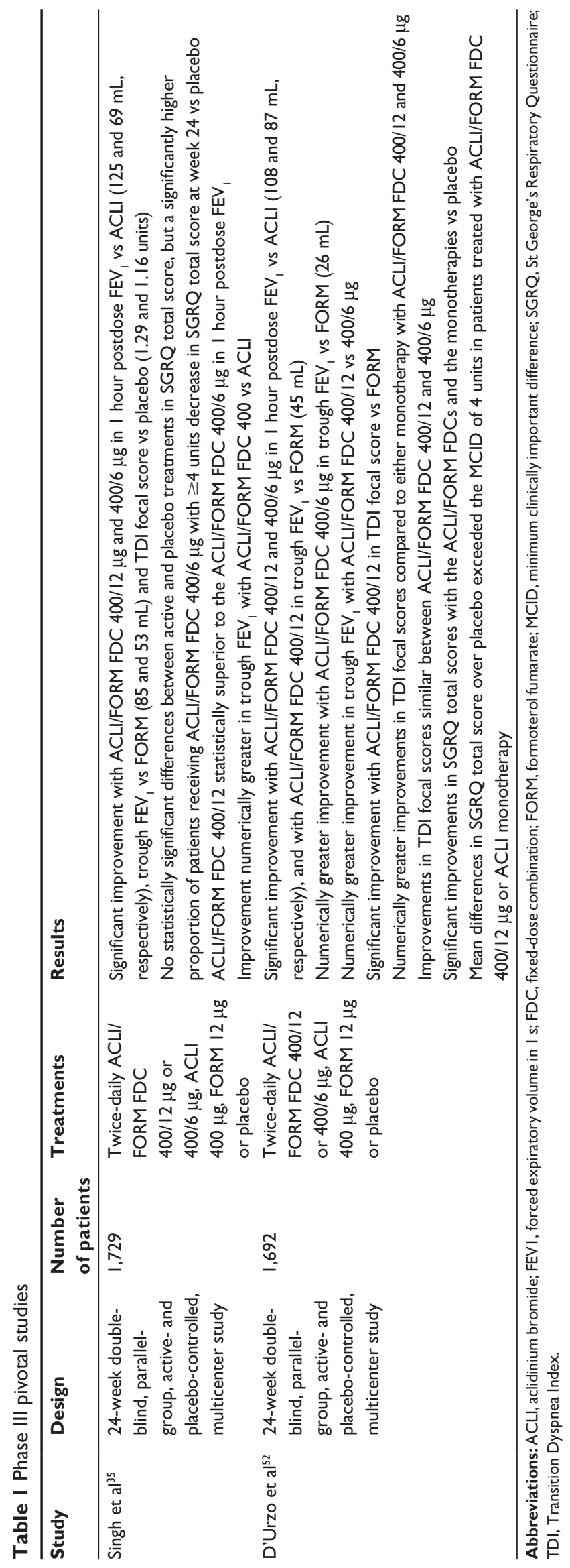


monotherapies. More patients treated with a FDC rather than either placebo or monotherapies achieved the minimum clinically important difference.

A second Phase III study, the ACLI/FORM combination for investiGative use in the treatMENT of moderate-to-severe COPD, conducted in 222 centers throughout North America, Australia, and New Zealand, replicated the same protocol (Table 1). ${ }^{52}$ The changes from baseline in overall average daily EXACT-RS scores were numerically improved for ACLI/FORM FDC 400/12 $\mu \mathrm{g}$ and significantly improved for ACLI/FORM FDC 400/6 $\mu \mathrm{g}$ vs either single agent. Patients in the ACLI/FORM FDC treatment groups reported greater reduction in overall nighttime COPD symptom severity vs placebo and either monotherapy at week 24, which was statistically significant for ACLI/FORM FDC 400/6 $\mu \mathrm{g}$ vs ACLI. At week 24, both ACLI/FORM FDCs significantly improved the average rating for overall early morning COPD symptom severity vs placebo and ACLI, but not vs FORM. Interestingly, the 28-week ACLI/FORM combination for investiGative use in the treatMENT trial extension for patients in the US and Canada documented that improvements in Transition Dyspnea Index focal score were numerically greater with ACLI/FORM (both doses) than with either constituent bronchodilator at all visits up to week $52^{53}$ and, even more important if focused on symptoms control, average daily rescue medication use over the course of the study was reduced compared with baseline. ${ }^{54}$

Data from these two large trials suggest that there is a benefit in using ACLI/FORM when our clinical target is the variability of symptoms, although the signal is not really very strong. In particular, the small difference in the impact on early morning COPD symptoms compared to monotherapy with FORM leaves us perplexed also because it contrasts with the documented faster and larger bronchodilation that is obtained when ACLI and FORM are coadministered compared to that elicited by the two single components. ${ }^{39}$ However, currently ACLI/FORM is the only LAMA/LABA FDC that has been studied for this therapeutic indication. In any case, the availability of a treatment that is able to control the variability of symptoms and mainly to reduce nighttime and/or early morning symptoms is extremely important. In fact, COPD patients with nighttime and/or early morning symptoms have lower health-related quality of life, while those with both report greater work productivity loss and greater activity impairment vs patients with no symptoms. ${ }^{46}$ Improved disease management may lower the economic impact on patients, employers, and the health care system.
In our opinion, ACLI/FORM FDC must be considered a useful, validated approach at least to the symptomatic treatment of COPD. We completely agree that better control of symptoms in the morning could benefit the patient throughout the day, leading to fewer periods of worsening symptoms and, in the longer term, fewer exacerbations. ${ }^{45}$ Roche et $\mathrm{al}^{45}$ have suggested that the chronic bronchitic phenotype might be the one that could take more advantage from a targeted treatment on symptoms.

Obviously, we cannot exclude that also other LAMA/ LABA FDCs, which are all once-daily FDCs, might be able to control the variability of COPD symptoms, mainly nighttime/ early morning symptoms. Unfortunately, there is still a lack of clear documentation that this is the case. Therefore, we are still waiting for a specifically designed trial that will allow us to establish whether twice-daily administration may be preferred to the once-daily dosing of bronchodilators mainly when twice-daily administration is administered in the evening or early in the morning. Regrettably, the wide availability of LAMA/LABA FDCs in the absence of head-to-head comparative pragmatic trials definitely makes difficult and, in any case, empiric, the choice of the combination to be used. Moreover, it is likely that these trials will not be carried out, both for their cost and the lack of interest that the pharmaceutical companies have to produce potential data that might be unfavorable to them. In any case, we believe that also any overlap between the chronic bronchitic phenotype and the putative "morning symptoms phenotype" as well as the impact of ACLI/FORM on this specific phenotype warrant further research.

\section{Disclosure}

MG Matera reports receiving personal fees from Almirall. A Sanduzzi reports receiving personal fees from Almirall and AstraZeneca. M Cazzola reports receiving grants and personal fees from Almirall and AstraZeneca.

\section{References}

1. Cazzola M, Di Marco F, Santus P, et al. The pharmacodynamic effects of single inhaled doses of formoterol, tiotropium and their combination in patients with COPD. Pulm Pharmacol Ther. 2004;17:35-39.

2. Cazzola M, Centanni S, Santus P. The functional impact of adding salmeterol and tiotropium in patients with stable COPD. Respir Med. 2004;98:1214-1221.

3. Cazzola M, Noschese P, Salzillo A, De Giglio C, D’Amato G, Matera MG. Bronchodilator response to formoterol after regular tiotropium or to tiotropium after regular formoterol in COPD patients. Respir Med. 2005 99:524-528.

4. Cazzola M, Tashkin DP. Combination of formoterol and tiotropium in the treatment of COPD: effects on lung function. COPD. 2009;6:404-415.

5. Beier J, van Noord J, Deans A, et al. Safety and efficacy of dual therapy with GSK233705 and salmeterol versus monotherapy with salmeterol, tiotropium, or placebo in a crossover pilot study in partially reversible COPD patients. Int J Chron Obstruct Pulmon Dis. 2012;7:153-164. 
6. Mahler DA, D’Urzo A, Bateman ED, et al. Concurrent use of indacaterol plus tiotropium in patients with COPD provides superior bronchodilation compared with tiotropium alone: a randomised, double-blind comparison. Thorax. 2012;67:781-788.

7. Matsushima $\mathrm{S}$, Inui $\mathrm{N}$, Yasui $\mathrm{H}$, et al. Indacaterol and tiotropium combination therapy in patients with chronic obstructive pulmonary disease. Pulm Pharmacol Ther. 2015;30:11-15.

8. van der Molen T, Cazzola M. Beyond lung function in COPD management: effectiveness of LABA/LAMA combination therapy on patientcentred outcomes. Prim Care Respir J. 2012;21:101-108.

9. Cazzola M, Page CP, Calzetta L, Matera MG. Pharmacology and therapeutics of bronchodilators. Pharmacol Rev. 2012;64:450-504.

10. Cazzola M, Molimard M. The scientific rationale for combining longacting beta2-agonists and muscarinic antagonists in COPD. Pulm Pharmacol Ther. 2010;23:257-267.

11. Calzetta L, Matera MG, Cazzola M. Pharmacological interaction between LABAs and LAMAs in the airways: optimizing synergy. Eur J Pharmacol. 2015;761:168-173.

12. Cazzola M, Rogliani P, Segreti A, Matera MG. An update on bronchodilators in Phase I and II clinical trials. Expert Opin Investig Drugs. 2012;21:1489-1501.

13. Tashkin DP. Future of fixed-dose longacting $\beta_{2}$-agonist and antimuscarinic combination therapy in COPD. Lancet Respir Med. 2013;1:6-7.

14. Singh D. New combination bronchodilators for chronic obstructive pulmonary disease: current evidence and future perspectives. Br J Clin Pharmacol. 2015;79:695-708.

15. Cazzola M, Page CP, Matera MG. Aclidinium bromide for the treatment of chronic obstructive pulmonary disease. Expert Opin Pharmacother. 2013;14:1205-1214.

16. Rogliani P, Calzetta L, Ora J, et al. Pharmacological assessment of the onset of action of aclidinium and glycopyrronium versus tiotropium in COPD patients and human isolated bronchi. Eur J Pharmacol. 2015; 761:383-390

17. Ni H, Soe Z, Moe S. Aclidinium bromide for stable chronic obstructive pulmonary disease. Cochrane Database Syst Rev. 2014;9:CD010509.

18. Cazzola M, Centanni S, Regorda C, et al. Onset of action of single doses of formoterol administered via Turbuhaler in patients with stable COPD. Pulm Pharmacol Ther. 2001;14:41-45.

19. Cazzola M, D'Amato M, Califano C, et al. Formoterol as dry powder oral inhalation compared with salbutamol metered-dose inhaler in acute exacerbations of chronic obstructive pulmonary disease. Clin Ther. 2002; 24:595-604

20. Cazzola M, Matera MG, Santangelo G, Vinciguerra A, Rossi F, D'Amato G. Salmeterol and formoterol in partially reversible severe chronic obstructive pulmonary disease: a dose-response study. Respir Med. 1995;89:357-362.

21. Steiropoulos P, Tzouvelekis A, Bouros D. Formoterol in the management of chronic obstructive pulmonary disease. Int J Chron Obstruct Pulmon Dis. 2008;3:205-215.

22. Cazzola M, Calzetta L, Page CP, et al. Pharmacological characterization of the interaction between aclidinium bromide and formoterol fumarate on human isolated bronchi. Eur J Pharmacol. 2014;745:135-143.

23. Cazzola M, Rogliani P, Matera MG. Aclidinium bromide/formoterol fumarate fixed-dose combination for the treatment of chronic obstructive pulmonary disease. Expert Opin Pharmacother. 2013;14:775-781.

24. Lal C, Strange C. Aclidinium bromide plus formoterol for the treatment of chronic obstructive pulmonary disease. Expert Opin Pharmacother. 2015;16:427-434

25. Babu KS, Morjaria JB. Clinicopharmacological profile of the fixeddose combination of aclidinium bromide and formoterol fumarate in the management of chronic obstructive pulmonary disease. Ther $A d v$ Respir Dis. 2015;9:56-68.

26. Cazzola M, Calzetta L, Matera MG. Aclidinium/formoterol fixed-dose combination for the treatment of chronic obstructive pulmonary disease. Drugs Today (Barc). 2015;51:97-105.

27. Moitra S, Bhome AB, Brashier BB. Aclidinium bromide/formoterol fixed-dose combination therapy for COPD: the evidence to date. Drug Des Devel Ther. 2015;9:1989-1999.
28. AstraZeneca Global. Duaklir ${ }^{\sqrt{B}}$ Genuair $^{\circledR}$ Approved in the European Union for Chronic Obstructive Pulmonary Disease. Available from: http://www.astrazeneca.com/Media/Press-releases/Article/20141124-duaklir-genuair-approved-in-the-european-union. Accessed July 10, 2015.

29. European Medicines Agency. Duaklir Genuair. Available from: http:// www.ema.europa.eu/ema/index.jsp?curl=pages/medicines/human/ medicines/003745/human_med_001811.jsp\&mid=WC0b01ac058001d124. Accessed July 10, 2015.

30. Price D, Robertson A, Bullen K, et al. Improved adherence with oncedaily versus twice-daily dosing of mometasone furoate administered via a dry powder inhaler: a randomized open-label study. BMC Pulm Med. 2010;10:1

31. Gordon J. GlaxoSmithKline - Upgrading to Neutral, Upside from Upcoming Catalysts Balances Out Earnings Risk. Available from: https://markets.jpmorgan.com/research/email/eevpt8pp/GPS1190044-0.pdf. Accessed July 9, 2015.

32. Beeh KM, Beier J. The short, the long and the "ultralong": why duration of bronchodilator action matters in chronic obstructive pulmonary disease. Adv Ther. 2010;27:150-159.

33. Cazzola M, Beeh KM, Price D, Roche N. Assessing the clinical value of fast onset and sustained duration of action of long-acting bronchodilators for COPD. Pulm Pharmacol Ther. 2015;31:68-78.

34. Wu K, Looby M, Pillai G, et al. Population pharmacodynamic model of the longitudinal $\mathrm{FEV}_{1}$ response to an inhaled long-acting antimuscarinic in COPD patients. J Pharmacokinet Pharmacodyn. 2011;38: 105-109.

35. Singh D, Jones PW, Bateman ED, et al. Efficacy and safety of aclidinium bromide/formoterol fumarate fixed-dose combinations compared with individual components and placebo in patients with COPD (ACLIFORM-COPD): a multicentre, randomised study. BMC Pulm Med. 2014;14:178.

36. Bateman ED, Ferguson GT, Barnes N, et al. Dual bronchodilation with QVA149 versus single bronchodilator therapy: the SHINE study. Eur Respir J. 2013;42:1484-1494.

37. Decramer M, Anzueto A, Kerwin E, et al. Efficacy and safety of umeclidinium plus vilanterol versus tiotropium, vilanterol, or umeclidinium monotherapies over 24 weeks in patients with chronic obstructive pulmonary disease: results from two multicentre, blinded, randomised controlled trials. Lancet Respir Med. 2014;2:472-486.

38. Buhl R, Maltais F, Abrahams R, et al. Tiotropium and olodaterol fixeddose combination versus mono-components in COPD (GOLD 2-4). Eur Respir J. 2015;45:969-979.

39. Cazzola M, Calzetta L, Ora J, Puxeddu E, Rogliani P, Matera MG. Searching for the synergistic effect between aclidinium and formoterol: from bench to bedside. Respir Med. 2015;109:1305-1311.

40. Di Marco F, Milic-Emili J, Boveri B, et al. Effect of inhaled bronchodilators on inspiratory capacity and dyspnoea at rest in COPD. Eur Respir J. 2003;21:86-94.

41. Kessler R, Partridge MR, Miravitlles M, et al. Symptom variability in patients with severe COPD: a pan-European cross-sectional study. Eur Respir J. 2011;37:264-272.

42. Mocarski M, Caracta C, Tourkodimitris S, et al. Nighttime symptoms of COPD in a clinical trial population: prevalence and impact [abstract]. Am J Respir Crit Care Med. 2011;183:A1495.

43. Price D, Small M, Milligan G, et al. Impact of night-time symptoms in COPD: a real-world study in five European countries. Int J Chron Obstruct Pulmon Dis. 2013;8:595-603.

44. Partridge MR, Karlsson N, Small IR. Patient insight into the impact of chronic obstructive pulmonary disease in the morning: an internet survey. Curr Med Res Opin. 2009;25:2043-2048.

45. Roche N, Small M, Broomfield S, et al. Real world COPD: association of morning symptoms with clinical and patient reported outcomes. COPD. 2013;10:679-686.

46. Stephenson JJ, Cai Q, Mocarski M, Tan H, Doshi JA, Sullivan SD. Impact and factors associated with nighttime and early morning symptoms among patients with chronic obstructive pulmonary disease. Int J Chron Obstruct Pulmon Dis. 2015;10:577-586. 
47. Kuyucu T, Güçlü SZ, Saylan B, et al. A cross-sectional observational study to investigate daily symptom variability, effects of symptom on morning activities and therapeutic expectations of patients and physicians in COPD-SUNRISE study. Tuberk Toraks. 2011;59:328-339.

48. Lopez-Campos JL, Calero C, Quintana-Gallego E. Symptom variability in COPD: a narrative review. Int J Chron Obstruct Pulmon Dis. 2013; 8:231-238

49. Leidy NK, Murray LT, Monz BU, et al. Measuring respiratory symptoms of COPD: performance of the EXACT-Respiratory Symptoms Tool (E-RS) in three clinical trials. Respir Res. 2014;15:124.

50. Mocarski M, Zaiser E, Trundell D, Make BJ, Hareendran A. Evaluation of the psychometric properties of the Nighttime Symptoms of COPD Instrument. Int J Chron Obstruct Pulmon Dis. 2015;10:475-487.

51. Mocarski M, Hareendran A, Jen MH, Zaiser E, Make B. Evaluation of the psychometric properties of the early morning symptoms of COPD instrument (EMSCI) [abstract]. Value Health. 2014;17:A179.
52. D'Urzo AD, Rennard SI, Kerwin EM, et al. Efficacy and safety of fixed-dose combinations of aclidinium bromide/formoterol fumarate: the 24-week, randomized, placebo-controlled AUGMENT COPD study. Respir Res. 2014;15:123.

53. D’Urzo AD, Rennard SI, Kerwin EM, He T, Leselbaum A, Caracta C. Efficacy of fixed-dose combination aclidinium bromide/formoterol fumarate on bronchodilation over 1 year: AUGMENT COPD extension trial in patients with moderate to severe COPD [abstract]. Am J Respir Crit Care Med. 2014;189:A6006.

54. Make B, Donohue J, Soong W, Zhong X, Leselbaum A, Caracta C. Efficacy and tolerability of aclidinium bromide/formoterol fumarate fixed-dose combination in patients with COPD: a 1-year study [abstract]. Eur Respir J. 2014;44(Suppl 58):P2413.

\section{Publish your work in this journal}

The International Journal of COPD is an international, peer-reviewed journal of therapeutics and pharmacology focusing on concise rapid reporting of clinical studies and reviews in COPD. Special focus is given to the pathophysiological processes underlying the disease, intervention programs, patient focused education, and self management protocols.

\section{Dovepress}

This journal is indexed on PubMed Central, MedLine and CAS. The manuscript management system is completely online and includes a very quick and fair peer-review system, which is all easy to use. Visit http://www.dovepress.com/testimonials.php to read real quotes from published authors.

Submit your manuscript here: http://www.dovepress.com/international-journal-of-chronic-obstructive-pulmonary-disease-journal 